\title{
Impact resistance of external thermal insulation systems
}

\author{
Ewa Sudoł ${ }^{1,{ }^{*}}$, Dawid Dębski ${ }^{2}$, Renata Zamorowska ${ }^{1}$, and Barbara Francke ${ }^{1}$ \\ ${ }^{1}$ Building Research Institute, Filtrowa St. 1, Warszawa 00-611, Poland \\ ${ }^{2}$ Atlas sp. z o.o., Kilińskiego St. 2, Łódź 91-421, Poland
}

\begin{abstract}
In the paper the results of an experimental program intended to determine factors influencing the impact resistance of the External Thermal Insulation Composite Systems (ETICS) were presented. For the research the systems based on polystyrene have been chosen. The insulation material was faced with a rendering consisting of base coat reinforced with standard or armored glass fibre mesh and silicone or silicone-silicate binders as finishing coats. The influence of various renderings components was evaluated with respect to resistance to hard body impact and resistance to hail. The test results were discussed in the context of the possible impact level on ETICS in use.
\end{abstract}

\section{Introduction}

External Thermal Insulation Composite Systems (ETICS) is one of the most popular method of improving the energy efficiency and refurbishing the façades of new and existing buildings, that has been widely used in Poland and Europe for last 60 years [1]. ETICS comprises a set of products including thermal insulation material - usually these are expanded polystyrene or mineral wool boards, adhesive intended for the attachment of the thermal insulation material to the substrate, anchors (if applied), rendering system consisting of reinforcement - standard or armored glass fibre mesh, base coat and finishing coat. Alternatively, it can also include key coat, impregnating agents and decorative coat.

One of the most important properties of the façade is its durability determined by the resistance to hygrothermal factors, biological corrosion and mechanical effects which include operational factors - accidental impacts of heavy objects and acts of vandalism and factors connected with weather conditions, in particular hail [2]. It is worth noting that according to European Severe Weather Database, around 400 cases of large hail (hailstones having a minimum diameter of $2 \mathrm{~cm}$ ) are reported in Poland annually [3].

Appropriately high impact resistance of the façade constructed with the ETICS is of significant importance not only for aesthetical reasons, but also for technical reasons. Even minor mechanical damage to the finishing coat makes it easier for the water to infiltrate the enclosure and lead to moisture accumulation within the façade. It speeds up the process of its degradation and any possible accumulation of moisture in the thermal insulation coat reduces the effectiveness of the thermal insulation.

\footnotetext{
* Corresponding author: e.sudol@itb.pl
} 
The solutions used in the modern ETICS lead to increased impact resistance of the facing coat. They include modifications in the area of the reinforcement coat involving the use of the flexible dispersion base coat, armored glass fibre mesh, as well as the new-generation organic thin coat finishing coats - silicate, silicone or silicone-silicate, which form a flexible, durable facing coat $[4,5]$.

The tests on ETICS focus mainly on the properties of individual above-mentioned components of thermal insulation systems [6]. Methods established to assess the performance of ETICS systems (described i.e. in ETAG 004 [7]), include only basic evaluation of system impact resistance, not taking into account more severe conditions of use like vandalism or hail resistance. Here we present the results of the study on the influence of particular component of the ETICS system on its overall impact resistance, according to standard and modified methods.

\section{Materials and methods}

The most common solution in Poland - expanded polystyrene (EPS) boards that comply with EN 13163 with the perpendicular tensile strength of $\geq 100 \mathrm{kPa}$ (EPS TR 100) and $\geq 80 \mathrm{kPa}$ (EPS TR 80) was selected for testing from among the thermal insulation materials.

The following were selected for the reinforcement from among the products:

- mineral I base coat which contained mineral fillers, cement, redispersible polymer powder, rheology modifiers, which requires addition of $21-23 \%$ (by weight) of water,

- mineral II base coat which contained mineral fillers, cement, redispersible polymer powder, rheology modifiers, which requires addition of $20-22 \%$ (by weight) of water,

- dispersion base coat which is a ready-to-use paste based on dispersion of polymer resins, fibres, modifiers and fillers.

A standard and armored glass fibre mesh was selected for the base coat reinforcement. The mesh characteristics are given in table 1 .

Table 1. Glass fibre mesh characteristic

\begin{tabular}{|c|c|c|c|c|}
\hline Type & $\begin{array}{c}\text { Mass per } \\
\text { unit area, } \\
\mathrm{kg} / \mathrm{m}^{2}\end{array}$ & $\begin{array}{c}\text { Mesh size, } \\
\mathrm{mm}\end{array}$ & $\begin{array}{c}\text { Residual } \\
\text { resistance after } \\
\text { alkalis ageing, } \\
\mathrm{N} / \mathrm{mm}\end{array}$ & $\begin{array}{c}\text { Relative residual } \\
\text { resistance, \%, (after alkalis } \\
\text { ageing) of the strength in the as } \\
\text { delivered state }\end{array}$ \\
\hline $\begin{array}{c}\text { mesh } \\
150\end{array}$ & 150 & $4.5 \times 5.0$ & $\geq 20$ & $\geq 50$ \\
\hline $\begin{array}{c}\text { mesh } \\
300\end{array}$ & 340 & $12.0 \times 13.0$ & $\geq 30$ & $\geq 50$ \\
\hline
\end{tabular}

The following finishing coats were selected:

- silicone I finishing coat which contained mineral fillers, silicone resin, hydrophobic agents, rheology modifiers, fibres and pigments,

- silicone II finishing coat which contained mineral fillers, silicone resin, hydrophobic agents, rheology modifiers, fibres and pigments,

- silicone-silicate finishing coat which contained mineral fillers, silicone resin, silicate resin, hydrophobic agents, rheology modifiers, fibres and pigments.

19 variants of complex thermal insulation systems were prepared using the abovementioned materials. Their configuration is presented in Table 2 . In the variants with the mineral base coat (U1-U5), a silicone key coat was applied before applying the finishing 
coat. In the variants with the dispersion base coat (U6-U21) no key coat was applied. No decorative coats were applied.

Table 2. Configuration of thermal insulation systems

\begin{tabular}{|c|c|c|c|c|}
\hline \multirow{2}{*}{ Variant } & \multicolumn{4}{|c|}{ Components } \\
\cline { 2 - 5 } & $\begin{array}{c}\text { insulation } \\
\text { product }\end{array}$ & base coat & glass fibre mesh & finishing coat \\
\hline U1 & EPS TR 100 & mineral I & $150-$ one layer & silicone I \\
\hline U2 & EPS TR 100 & mineral I & $150-$ one layer & silicone II \\
\hline U3 & EPS TR 100 & mineral I & $150-$ one layer & silicone-silicate \\
\hline U4 & EPS TR 100 & mineral II & $150-$ one layer & silicone I \\
\hline U5 & ESP TR 100 & mineral II & $150-$ one layer & silicone II \\
\hline U6 & EPS TR 100 & dispersion & $150-$ one layer & silicone I \\
\hline U7 & EPS TR 100 & dispersion & $150-$ one layer & silicone II \\
\hline U8 & EPS TR 100 & dispersion & $150-$ one layer & silicone-silicate \\
\hline U10 & EPS TR 100 & dispersion & $150-$ two layers & silicone I \\
\hline U11 & EPS TR 100 & dispersion & $150-$ two layers & silicone II \\
\hline U12 & EPSTR 100 & dispersion & $150-$ two layers & silicone-silicate \\
\hline U13 & EPS TR 100 & dispersion & $150-$ one layer & silicone I \\
\hline U14 & EPS TR 100 & dispersion & $150-$ one layer & silicone II \\
\hline U15 & EPS TR 100 & dispersion & $150-$ one layer & silicone-silicate \\
\hline U16 & EPS TR 80 & dispersion & $150-$ one layer & silicone I \\
\hline U17 & EPS TR 80 & dispersion & $150-$ one layer & silicone II \\
\hline U18 & EPS TR 80 & dispersion & $150-$ one layer & silicone-silicate \\
\hline U19 & EPS TR 80 & dispersion & $150-$ two layers & silicone-silicate \\
\hline
\end{tabular}

2 models with the dimensions of $0.5 \times 1.0 \mathrm{~m}$, with the use of $0.05 \mathrm{~m}$ thick EPS, were prepared for each variant. The models were prepared in laboratory conditions $\left(\mathrm{T} 23 \pm 2^{\circ} \mathrm{C}\right.$ and RH $50 \pm 5 \%$ ), according to the technology specified for individual solutions. They were seasoned for 28 days in the preparation conditions.

The following properties of the ETICS were determined:

- resistance to hard body impact,

- resistance to hail.

The resistance to hard body impact test was carried out for all the variants of the ETICS, whereas the resistance to hail for the systems with EPS 100, a single layer of 150 mesh and silicone finishing coats.

The resistance to hard body impact test was carried out on specimens with the dimensions of $0.5 \times 0.5 \mathrm{~m}$, whereas the resistance to hail test on specimens of $0.25 \times 0.25 \mathrm{~m}$, cut out from the models after completion of the seasoning. The edges of the specimens collected for the resistance to hard body impact test were covered with the epoxy resin for protection.

The resistance to hard body impact test was performed on the basis of ISO 7892. The steel balls with the weight ranging from $0.5 \mathrm{~kg}$ to $4.7 \mathrm{~kg}$ were used in the test. The balls were dropped from the height ranging from $0.61 \mathrm{~m}$ to $3.0 \mathrm{~m}$, appropriately to the adopted impact energy level. Before the test, the specimens were immersed in water for 7 days and then seasoned for 7 days in laboratory conditions (T23 $22^{\circ} \mathrm{C}$ and $\mathrm{RH} 50 \pm 5 \%$ ). The specimens were placed on a stable surface with their facing towards the direction of the ball movement, while ensuring the stability of their position during the test. A steel ball was dropped freely from the height appropriate for the adopted impact energy level. The test was started with the impact with the energy of $3 \mathrm{~J}$ (the ball of $0.5 \mathrm{~kg}$, the fall height of $0.61 \mathrm{~m}$ ), and if the specimen 
was not damaged, the test was continued while increasing the impact energy (increasing the weight of the ball and/or the fall height) until the damage occurred. Any cracks, scaling, debonding between layers visible to a naked eye were considered as damage. Any possible permanent deformation that was not accompanied by the above-mentioned features, was not considered as damage. The test was carried out in the above-mentioned laboratory conditions. The result of the test is the maximum impact energy, at which no damage to the ETICS was found in five tests.

The resistance to hail test was made on the basis of PN-EN 13583. The hail impact was simulated with the use of a polyamide ball with a smooth surface, the weight of $38.5 \pm 0.5 \mathrm{~g}$ and the diameter of $40 \pm 0.5 \mathrm{~mm}$. First the specimens were seasoned for $24 \mathrm{~h}$ at $\mathrm{T} 23 \pm 2^{\circ} \mathrm{C}$ and RH $50 \pm 5 \%$, then they were placed horizontally in the testing apparatus, with their facing towards the direction of the ball movement, while ensuring the stability of their position during the test. The polyamide ball was shot perpendicularly to the specimen surface at the speed of $2 \mathrm{~m} / \mathrm{s}$. If the specimen was not damaged at this speed, the test was continued while increasing the shot speed until the damage occurred. The same properties as during the hard body impact resistance test were considered as damage. The test was carried out in the abovementioned laboratory conditions. The result of the test is the maximum speed at which the ball hits without causing any damage to the ETICS, confirmed in five tests.

\section{Results and disscusion}

The analysis of the results of the hard body impact resistance tests on the ETICS made with the use of EPS TR 100 and a single layer of glass fibre mesh 150 (Fig. 1) indicated that in the solutions where the mineral base coat was used, the type of finishing coat was the factor determining the resistance. The systems with the silicone I finishing coat were characterised by the resistance to impact with the energy of $20 \mathrm{~J}$, while the remaining variants - with the silicone II finishing coat and the silicone-silicate finishing coat - had the resistance of $3 \mathrm{~J}$. For the system with the dispersion base coat, the relations of the solution with both silicone finishing coat were characterised by the resistance of $20 \mathrm{~J}$, whole the system with the silicatesilione finishing coat showed the resistance of $10 \mathrm{~J}$. It should be also noticed that in the case of the solutions with the silicone II finishing coat and the silicone-silicate finishing coat, an increase in the impact resistance was observed when the mineral base coat was replaced with the dispersion base coat. There was no change for the systems with the silicone I finishing coat.

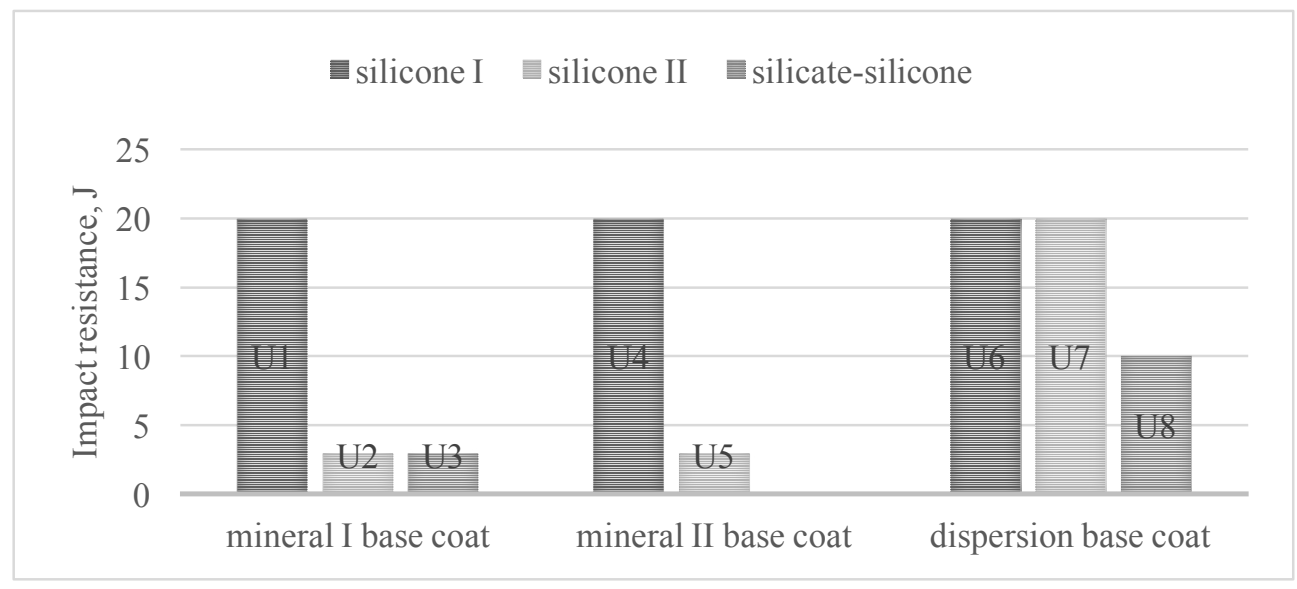

Fig. 1. The hard body impact resistance of the ETICS made with the use of EPS TR 100 and a single layer of glass fibre mesh 150 depending on the type of the base coat and finishing coat. 
Selected samples after hard body impact resistance test are presented in Fig. 2.
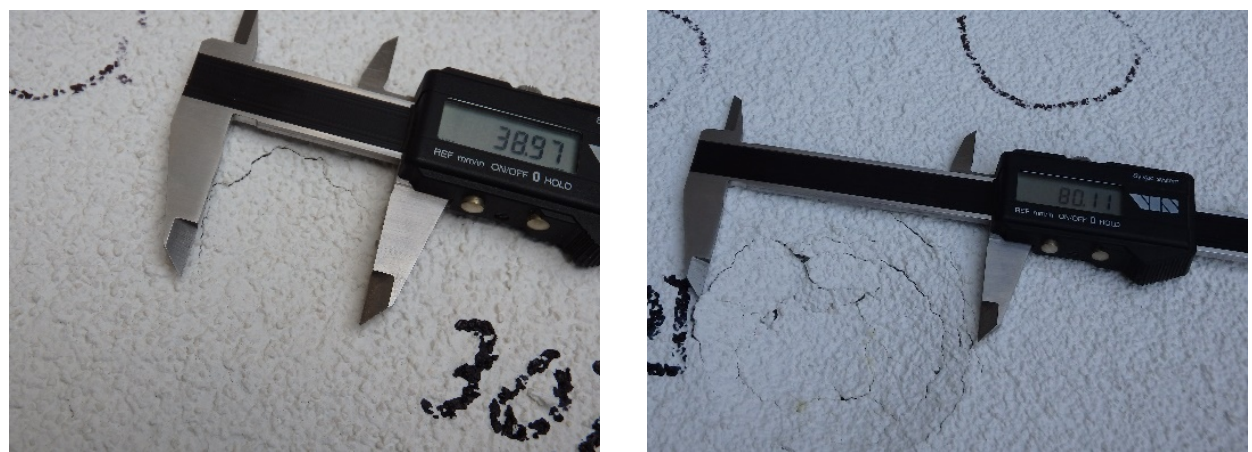

a)

Fig. 2. Samples after hard body impact resistance test a) variant U1 - cracks at the circumference after impact with energy $30 \mathrm{~J}, \mathrm{~b}$ ) variant $\mathrm{U} 4$ - cracks at the impact point and at the circumference after impact with energy $50 \mathrm{~J}$.

The application of the reinforced mesh resulted, as expected, in a significant increase in the impact resistance of the system (Fig. 3). The systems made with the use of EPS TR 100 and the dispersion base coat, where a single layer of mesh 150 was used, were characterised by the resistance of $10 \mathrm{~J}$ - the systems with silicone finishing coats or $20 \mathrm{~J}$ - the system with silicone-silicate finishing coat. The application of the additional layer of the same mesh resulted in resistance increase to $30 \mathrm{~J}$ and to $70 \mathrm{~J}$ respectively. The use of the armored glass fibre meshes 300 , together with the standard mesh 150, allowed to increase the resistance of the ETICS to as much as $120 \mathrm{~J}$ for the solutions with the silicone I finishing coat and siliconesilicate finishing coat and to $140 \mathrm{~J}$ for the solutions with silicone II finishing coat. The results are correlated with the tensile strength of the reinforced layer made with different types of reinforcement [6].

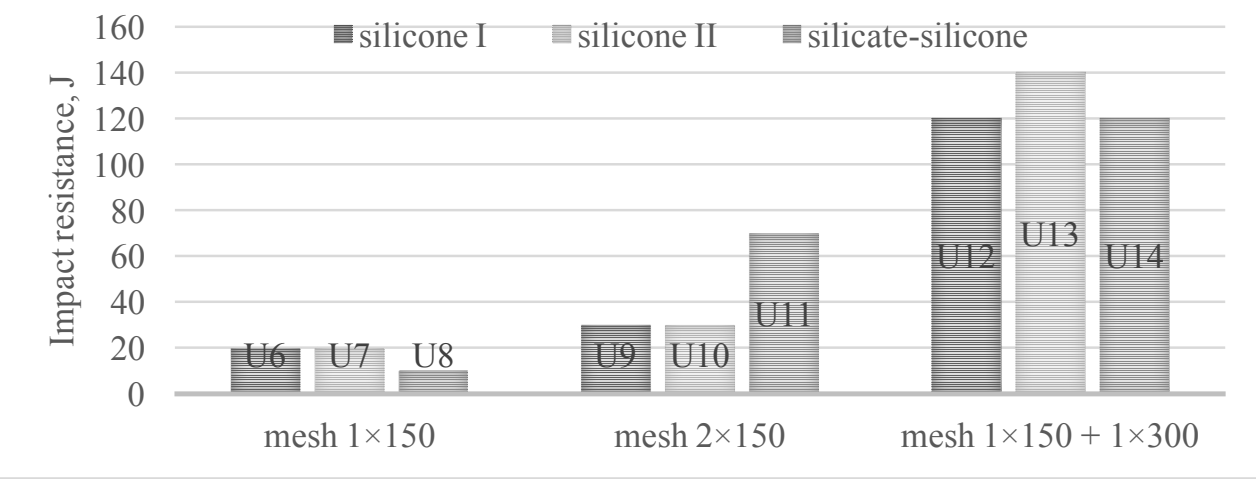

Fig. 3. The hard body impact resistance of the ETICS made with the use of EPS TR 100 and the dispersion base coat depending on the type of the glass fibre mesh and finishing coat.

When comparing the results of the impact resistance tests obtained for the systems made with the use of EPS TR 100 and EPS TR 80 it was found that the type of the expanded polystyrene - in view of the scope under consideration, typical for the ETICS - had an effect on the characteristics under consideration. The systems with the EPS TR 100 with silicone finishing coats were characterised by the resistance to impact with the energy of $20 \mathrm{~J}$, while 
the systems with EPS TR 80 had the resistance of $10 \mathrm{~J}$. The above was observed for the systems with the dispersion base coat, for all the types of finishing coat under consideration (Fig. 4).

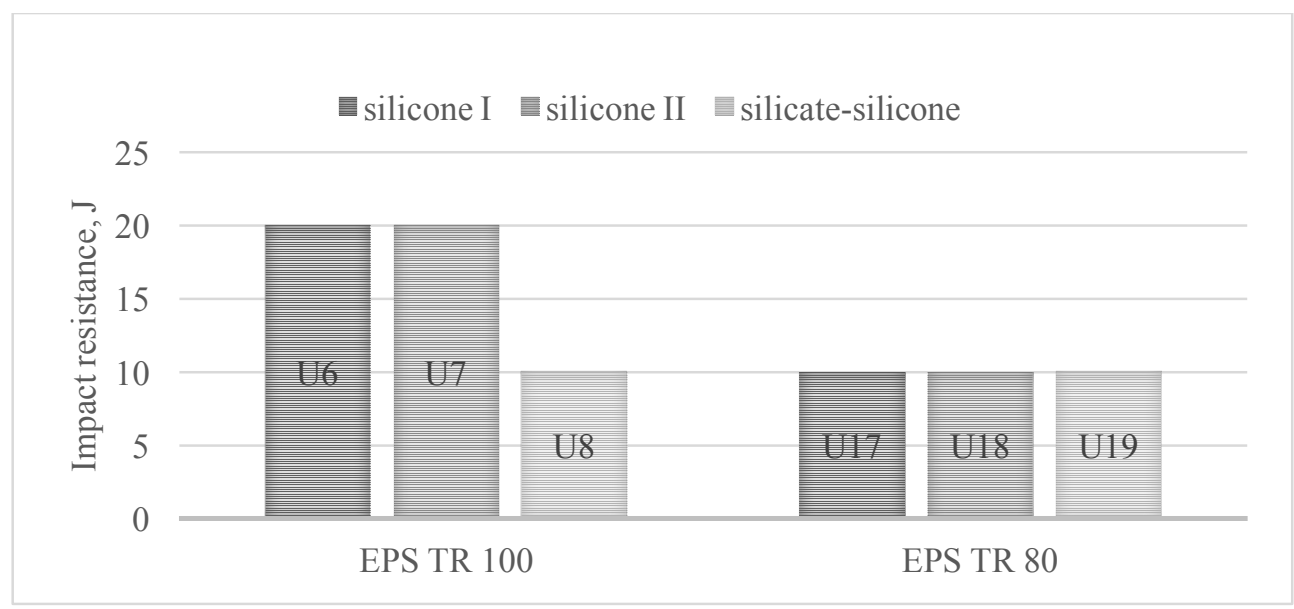

Fig. 4. The hard body impact resistance of the ETICS made with the use of the dispersion base coat and a single layer of glass fibre mesh 150, depending on the type of the finishing coat and insulation product

Similar relations were noted when analysing chosen systems with different reinforcement of the dispersion base coat - the solutions with the silicone II finishing coat and single layer of mesh 150 and (Fig. 5a) and the systems with the silicone-silicate finishing coat and double layer of mesh 150 (Fig. 5b). In other systems the impact resistance for both types of EPS was kept at the same level.
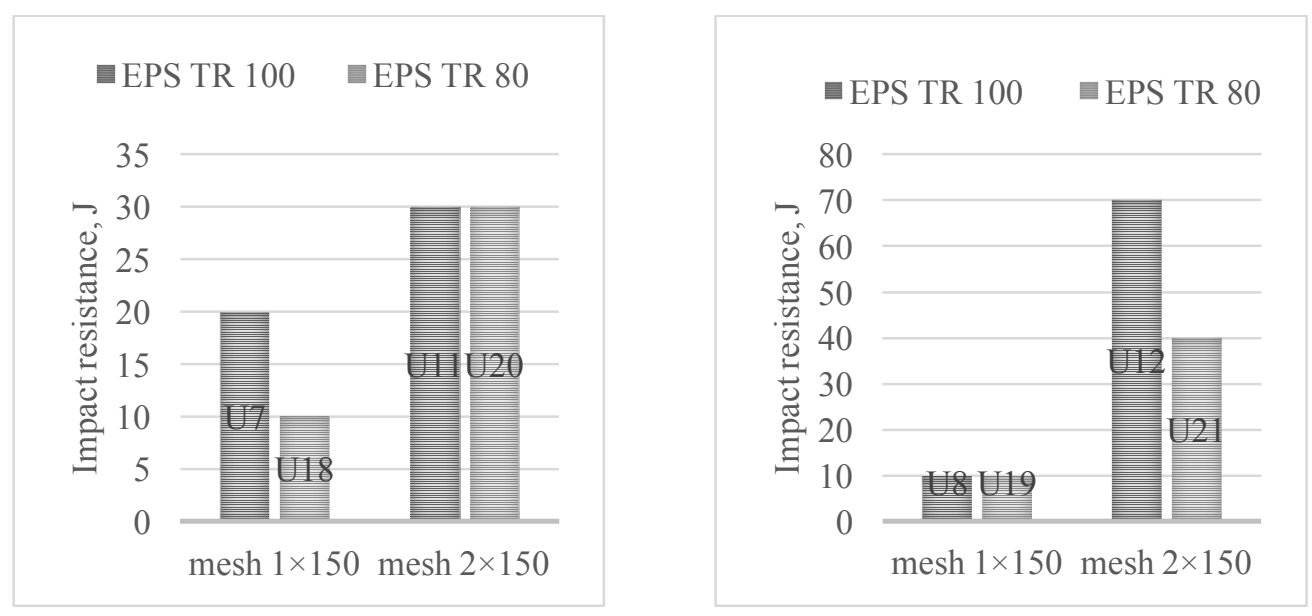

a)

b)

Fig. 5. The hard body impact resistance of the ETICS made with the use of the dispersion base coat and finishing coat a) silicone II, b) silicone-silicate depending on the type of the glass fibre mesh and insulation product

Summarising the results of the resistance to hard body impact tests it can be stated the majority of the tested ETICS solutions were characterised by the resistance of at least $10 \mathrm{~J}$, which allows to classify them as appropriate for use in use category I, i.e. in the area that is readily accessible at ground level to the public and vulnerable to hard body impacts but not subjected to abnormally rough use. Only the solutions with the mineral base coat and the 
finishing coat other than silicone I, with the impact resistance of $3 \mathrm{~J}$, can be classified as appropriate for use only in the use category II, that is in the area which is liable to impacts from thrown or kicked objects, but in public locations where the height of the ETICS will limit the size of the impact; or at lower levels where access to the building is primarily to those with some incentive to exercise care. At the same time, having in mind the extremely high values of the impact resistance of some of the solutions, even over $100 \mathrm{~J}$, it can be assumed that they are appropriate for use even in the areas exposed to the above-average risk of a severe hard body impact, i.e. next to the sport infrastructure - located close to pitches and playgrounds, or around the entrances of staircases, on plinths, etc.

Analysis of the results of the tests of hail resistance of the ETICS carried out for the systems made with the use of EPS TR 100 and the weakest variant of the reinforcement in the form of a single layer of glass fibre mesh 150 (Fig. 6), shows that there is a slight effect of the finishing coat type on the characteristics under examinations in the case of the systems with the mineral base coat. The systems with the silicone I finishing coat achieved the resistance to hail of $10 \mathrm{~m} / \mathrm{s}$ - mineral I base coat and $6 \mathrm{~m} / \mathrm{s}$ - mineral II base coat, whereas those with silicone II finishing coat, a slightly smaller resistance $-7 \mathrm{~m} / \mathrm{s}$ and $5 \mathrm{~m} / \mathrm{s}$ respectively. These results correspond to the resistance to hard body impact (Fig. 1). In the case of the systems with the dispersion base coat, where the most advantageous characteristics were expected, a surprisingly low result was obtained for the silicone I finishing coat $-5 \mathrm{~m} / \mathrm{s}$. Obtaining such remarkably low result for this system (especially in comparison with hard body impact test results) may suggest some abnormality in the test, such as dissimilarity of the sample preparation or other issue, and additional investigation for that case is required. The hail resistance of the variant with the silicone II finishing coat was high $-22 \mathrm{~m} / \mathrm{s}$, which allows to consider this solution as resistant to impacts resulting from extreme weather conditions.

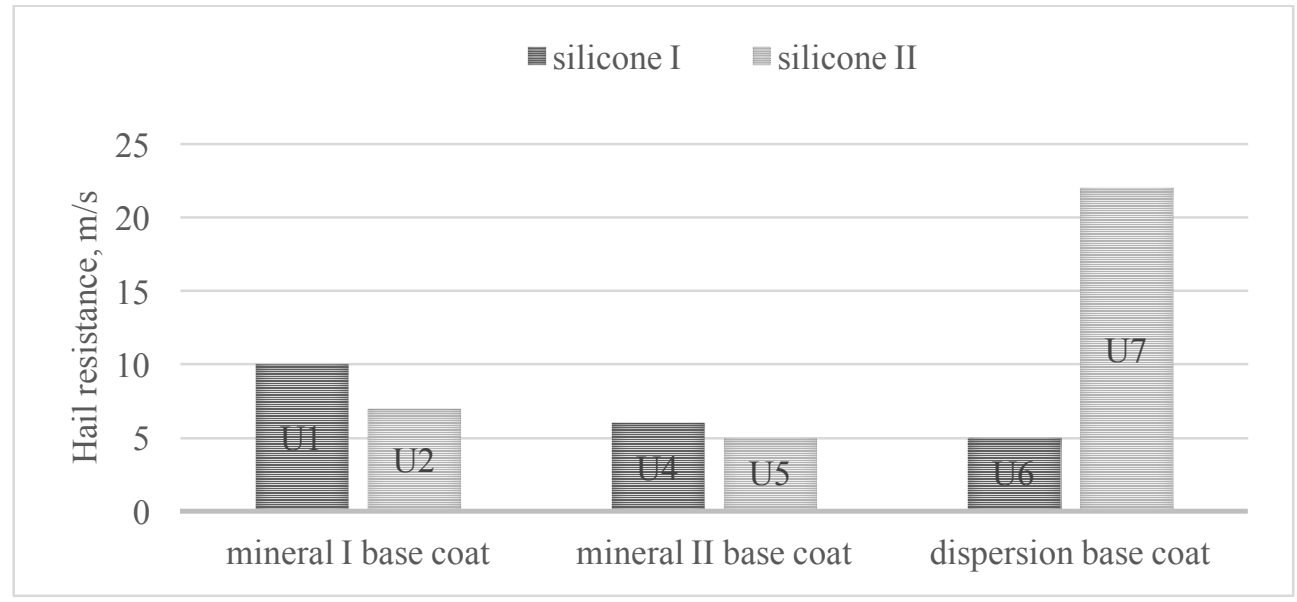

Fig. 6. The hail resistance of the ETICS made with the use of EPS TR100 and a single layer of glass fibre mesh 150 depending on the type of the base coat and finishing coat

\section{Summary and conclusion}

The research carried out on the External Thermal Insulation Composite Systems (ETICS) confirms that these solutions, with the appropriate system configuration, are characterised by very high resistance to hard body impact. Some of them achieved the resistance of over $100 \mathrm{~J}$ which allows to conclude that they are suitable for use even in the areas exposed to the above-average risk of a severe hard body impact. The tests showed the advantageous effect 
of the dispersion base coat and the armored mesh on the resistance to hard body impact. The advantage of the EPS TR 100 over EPS TR 80 was visible.

High results of the hail resistance of selected ETICS solutions indicate that they are resistant to impact resulting from weather conditions. However, this area of research needs to be expanded by carrying out further tests.

\section{References}

1. E. Barreira, V. P. de Freitas, External Thermal Insulation Composite Systems (ETICS). An Evaluation of Hydrothermal Behavior (Springer, 2015)

2. A. Wanat, Izolacje 22, 78 (2017)

3. N. Dotzek, P. Groenemeijer, B. Feuerstein, A.M. Holzer, Atmos. Res. 93, 575 (2009)

4. T. Buczek, Modern Eng. 1, 16 (2016)

5. S. Zalewski, Izolacje 21, 42 (2016)

6. P. Konca, M. Koniorczyk, A. Zawadowska, Izolacje 20, 68 (2015)

7. ETAG 004 External Thermal Insulation Composite Systems (ETICS) with Rendering (EOTA, 2013) 